\title{
Modelling and observations of the katabatic flow dynamics over Greenland
}

\author{
By GÜNTHER HEINEMANN ${ }^{1 *}$ and THOMAS KLEIN ${ }^{2},{ }^{1}$ Meteorologisches Institut Universität Bonn, Auf \\ dem Hügel 20, D-53121 Bonn, Germany; ${ }^{2}$ Swedish Meteorological and Hydrological Institute, S-60176 \\ Norrköping, Sweden
}

(Manuscript received 28 November 2001; in final form 25 March 2002)

\begin{abstract}
The katabatic wind system over the Greenland ice sheet is studied using simulations of the hydrostatic Norwegian Limited Area Model (NORLAM) and measurements of an instrumented aircraft. The structure and the dynamics of the katabatic wind over the ice sheet are investigated for a case study of the aircraft-based experiment KABEG (Katabatic wind and boundary layer front experiment around Greenland) in the area of southern Greenland in April/May 1997. Monthly mean structures and individual contributions of the momentum budget integrated over the boundary layer are examined for one winter month. The NORLAM is able to simulate realistically the structures of the katabatic wind system in the lowest $400 \mathrm{~m}$. The comparison with KABEG aircraft measurements for a katabatic wind case with strong synoptic forcing shows good agreement for the momentum budget terms. The pure katabatic force represents the main mechanism for the boundary layer wind field, but a considerable influence of the large-scale synoptic forcing is found as well. Acceleration components from the NORLAM forecasts are also presented for the whole month of January 1990. The monthly mean fields show significant regional differences because of different inversion strengths and synoptic forcings. In particular, Southeast Greenland is influenced by transient synoptic cyclones and the associated cloud patterns. All other areas of the slopes of the Greenland ice sheet are characterized by a downslope katabatic acceleration. The pressure gradient force over the northwestern part of the Greenland ice sheet points in the direction of the local katabatic force, which explains the relatively strong monthly mean near surface winds over the ice. Over the southwestern and northeastern parts of Greenland, however, no significant synoptic support of the katabatic winds is present, and the synoptic pressure gradient is even opposed to the katabatic force in some regions.
\end{abstract}

\section{Introduction}

The near-surface climate of the ice sheets of Antarctica and Greenland is strongly influenced by the energy and momentum exchange at the air/snow interface. A generally stable stratification over the ice slopes leads to the development of a katabatic wind system with windspeeds of $20 \mathrm{~m} \mathrm{~s}^{-1}$ and more, which enhances air/snow interaction processes. A knowledge of katabatic flow dynamics is therefore important for

${ }^{*}$ Corresponding author. e-mail: gheinemann@uni-bonn.de questions of the mass balance of the ice sheets, and also for an understanding of the global momentum budget.

In the present paper, katabatic flow dynamics are investigated for the Greenland ice sheet. The areal coverage of this ice sheet is about $1.75 \times 10^{6} \mathrm{~km}^{2}$, which is relatively small compared to its Antarctic counterpart, but a number of important processes are associated with the katabatic wind in the Greenland area (Fig. 1). In connection with an additional synoptic pressure gradient katabatic winds can reach hazardous strength. These katabatic storms, called 'Piteraqs' by the Inuit, can occur at the southeastern coast of Greenland (Rasmussen, 1989). Furthermore, the katabatic winds at the East Greenland coast near Angmagssalik 


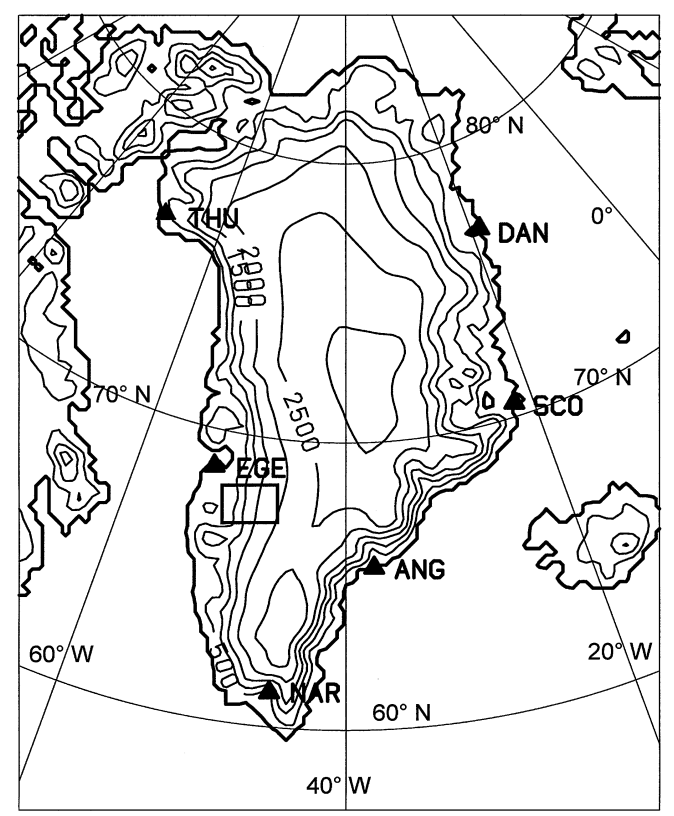

Fig. 1. Model domain of the LAM25 with orography (isolines every $500 \mathrm{~m}$ ). The box marks the KABEG area near Kangerlussuaq shown in Fig. 2 in detail. Greenland radiosonde stations are marked by triangles (NAR, Narssarssuaq; EGE, Egedesminde; THU, Thule Airbase; DAN, Danmarkshavn; SCO, Scoresbysund; ANG, Angmagssalik/ Tasiilaq).

(Tasiilaq, see Fig. 1) seem to be important for the development of mesoscale cyclones in this area (Klein and Heinemann, 2002). Since the near-surface climate over the sloped ice sheet is determined by boundary layer processes (a pure katabatic regime) as well as by synoptic processes to a large extent, an important question concerning the katabatic flow dynamics is the quantitative importance of these two main factors.

First studies to investigate experimentally katabatic wind dynamics over the West Greenland ice sheet were shown by Van den Broeke et al. (1994) for a summertime situation during the Greenland Ice Margin Experiment (GIMEX, Oerlemans und Vugts, 1993). In the same area, the aircraft-based experiment KABEG (Katabatic wind and boundary layer front experiment around Greenland) was performed in April/May 1997 (Heinemann, 1998; 1999). Studies of the boundary layer dynamics based on single aircraft profiles yielded the results that the katabatic flow was always shooting (Froude number larger than 1) and that the katabatic force is the main driving mechanism for the flow regime (Heinemann, 1999).
While a number of mesoscale model studies have been carried out for Greenland (e.g. Bromwich et al., 1996; Van den Broeke and Gallée, 1996; Bromwich et al., 2001; Klein et al., 2001), a model-based investigation of the katabatic wind dynamics is presently not available. For the Antarctic, a first attempt to study the momentum budget of the katabatic wind layer was shown by Bromwich et al. (1994) using idealized simulations. A longer term study of katabatic flow dynamics for the Antarctic using realistic boundary conditions was shown by Van den Broeke et al. (2002).

The design of the present paper is as follows: Section 2 describes the model and the experimental data. In Section 3, a simulation for a strong katabatic wind event during the KABEG period is presented. Model simulations of the boundary layer structure and terms of the momentum budget are validated against observational data. Monthly mean structures and individual contributions of the momentum budget integrated over the boundary layer are examined for one winter month in Section 4. Conclusions are given in the last section.

\section{Experimental data and model description}

\subsection{KABEG experiment}

The aircraft-based experiment KABEG was performed during April/May 1997 in the area of South Greenland. The base of the aircraft was Kangerlussuaq (former Søndre Strømfjord, West Greenland, Fig. 1). Surface stations were installed at five positions (A1A4 and S in Fig. 2). Station A4 was furthest from the edge of the ice sheet (at a distance of $75 \mathrm{~km}$ to the ice edge, $1600 \mathrm{~m} \mathrm{ASL}$ ). Aircraft data were collected by the research aircraft POLAR2 (Dornier 228) owned by the Alfred-Wegener-Institut (Bremerhaven, Germany). The GPS-navigated aircraft measured position, wind vector, air temperature and humidity with several instruments with sampling rates between 12 and $120 \mathrm{~Hz}$ (for details about instrumentation and flights see Heinemann, 1999; Klein et al., 2001; Heinemann, 2002).

\subsection{The numerical model}

The limited area primitive equation model NORLAM is used in this study. NORLAM is the former operational model of the Norwegian Meteorological Institute (DNMI) at Oslo. This model has been successfully applied for the simulation of katabatic winds 


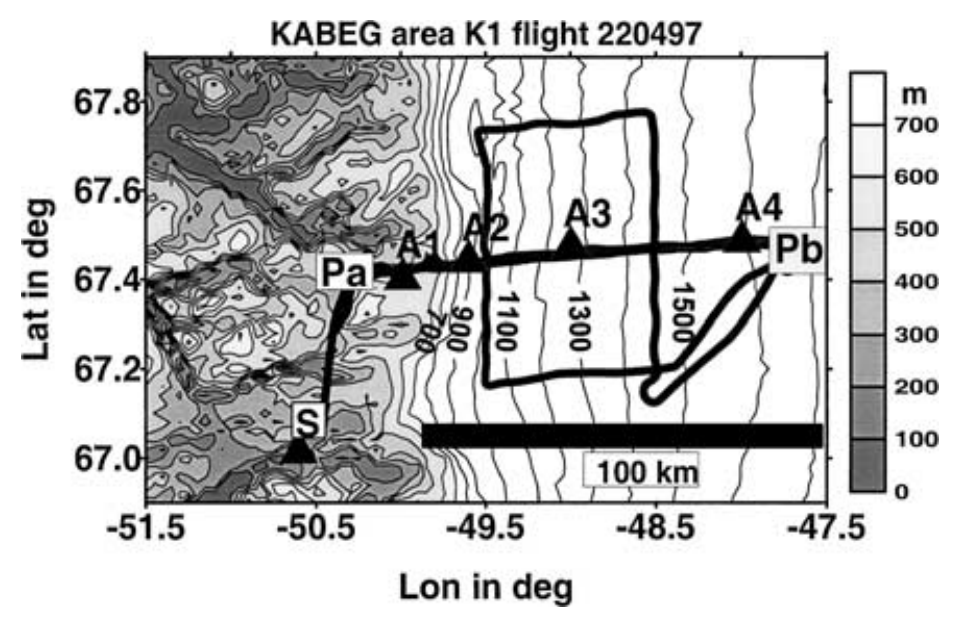

Fig. 2. Area of the KABEG flight program near Kangerlussuaq with a high-resolution (2 km) topography (Ekholm, 1996). Isolines are drawn every $100 \mathrm{~m}$, areas lower than $700 \mathrm{~m}$ are shaded. The triangles mark the positions of the KABEG surface stations A1-A4 and S (Kangerlussuaq). The flight path of the flight on 22 April 1997 is superimposed, the main measurement line $\mathrm{P}(\mathrm{Pa}-\mathrm{Pb})$ is indicated.

and other mesoscale phenomena in the Arctic and Antarctic (e.g. Grønås et al., 1987; Grønås and Skeie, 1999; Klein and Heinemann, 2002; Klein et al., 2001). General information on the model can be found in Grønås and Hellevik (1982), while Nordeng (1986) provides a description of the basic model physics and parameterization schemes.

The configuration of NORLAM as used here is identical with that described in Klein et al. (2001). Resolutions of 50 and $25 \mathrm{~km}$ are used in a nested mode. Global analyses of the European Centre for Mediumrange Weather Forecasts (ECMWF) are used as initial and boundary fields for the NORLAM runs, with a grid spacing of $50 \mathrm{~km}$ (LAM50). Runs with $25 \mathrm{~km}$ grid spacing (LAM25) are then performed with the results of the LAM50 run as boundary conditions, using the $0 \mathrm{~h}$ initialized LAM50 analysis as initial state. The model is used with a domain size of $121 \times 97$ grid points for the LAM50 and LAM25 simulations. The model domains are $6000 \mathrm{~km} \times 5000 \mathrm{~km}$ (LAM50) and $2500 \mathrm{~km} \times 3000 \mathrm{~km}$ (LAM25, see Fig. 1).

For the simulation of the katabatic wind system during the individual KABEG cases, a vertical resolution of NORLAM of $40 \sigma$-levels was used. A very good resolution of the boundary layer is achieved, since 18 of the $40 \sigma$-levels are located in the lowest $400 \mathrm{~m}$ of the atmosphere, with five levels covering the lowest $100 \mathrm{~m}$ (lowest level at $10 \mathrm{~m}$ ). The months of the KABEG experiment (April and May 1997) and January 1990 were completely simulated with a vertical resolution of 30 $\sigma$-levels (with about half the levels located below $850 \mathrm{hPa}$, the lowest level at $30 \mathrm{~m}$ ). For these monthly runs the model was operated in a forecast mode, i.e. it was restarted with a new ECMWF analysis at 0000 UTC every day and integrated forward in time for $48 \mathrm{~h}$. Therefore, each day of the month apart from the first day is covered by integrations twice.

\subsection{Methodology for the investigation of katabatic wind dynamics}

The dynamics of the katabatic wind layer are investigated using the concept of the two-layer katabatic wind model according to Ball (1956). An overview over these types of boundary layer models is given in Mahrt (1982). Despite the simplicity of the Ball model, it has been successfully applied to derive the basic near-surface flow pattern over Antarctica (Parish and Bromwich, 1987).

Following Ball (1956), the vertical integration of the horizontal momentum budget equation from the surface $\left(z_{\mathrm{s}}\right)$ to the top of the boundary layer $(h)$ yields:

$$
\begin{aligned}
\frac{\mathrm{d} \boldsymbol{V}_{\mathrm{m}}}{\mathrm{d} t} & =-\frac{1}{\rho_{\mathrm{m}}} \nabla p-f \boldsymbol{k} \times \boldsymbol{V}_{\mathrm{m}}-\frac{1}{\rho_{\mathrm{m}} h} \boldsymbol{\tau}\left(z_{\mathrm{s}}\right) \\
& =\boldsymbol{F}_{\mathbf{p}}+\boldsymbol{F}_{\mathbf{C}}+\boldsymbol{F}_{\mathbf{R}} .
\end{aligned}
$$

$\boldsymbol{V}_{\mathrm{m}}$ is the horizontal wind vector tangential to the slope, $\rho_{\mathrm{m}}$ is the air density (the index $\mathrm{m}$ indicates the mean over the katabatic wind layer of height $h$ ), and $p$ is 
the pressure. The forces on the right-hand side are the two-dimensional pressure gradient force, the Coriolis force $(f=$ Coriolis parameter $)$ and friction $\left[\tau\left(\mathrm{z}_{\mathrm{s}}\right)\right.$ is the surface momentum flux vector]. The pressure gradient force can be split into different contributions:

$$
\begin{aligned}
F_{\mathrm{p}}= & -\frac{1}{\rho_{\mathrm{m}}} \nabla P-g \frac{\Delta \theta_{\mathrm{m}}}{\theta_{\mathrm{m}}} \nabla z_{\mathrm{s}}-g \frac{\Delta \theta_{\mathrm{m}}}{\theta_{\mathrm{m}}} \nabla h \\
& -g \frac{h}{\theta_{\mathrm{m}}} \nabla\left(\Delta \theta_{\mathrm{m}}\right)=F_{\mathrm{S}}+F_{\mathrm{T}}+F_{\mathrm{I}}+F_{\mathrm{DI}}
\end{aligned}
$$

where $g$ is the acceleration due to gravity, $P$ is the superimposed synoptic pressure, $\Delta \theta_{\mathrm{m}}$ is the inversion strength (or temperature deficit of the katabatic wind layer), $\theta_{\mathrm{m}}$ is the mean potential temperature, and $\nabla z_{\mathrm{s}}$ is the terrain gradient. The first term on the right-hand side represents the superimposed synoptic pressure gradient force, and the second is the classical katabatic pressure gradient force due to the terrain slope. The third and fourth terms result from inhomogeneities of the height of the katabatic wind layer and the inversion strength, respectively.

The one-dimensional form of Eq. (2) reads as:

$$
\begin{aligned}
F_{\mathrm{p}, \mathrm{x}}= & -\frac{1}{\rho_{\mathrm{m}}} \frac{\partial P}{\partial x}+g \frac{\Delta \theta_{\mathrm{m}}}{\theta_{\mathrm{m}}} \alpha-g \frac{\Delta \theta_{\mathrm{m}}}{\theta_{\mathrm{m}}} \frac{\partial h}{\partial x} \\
& -g \frac{h}{\theta_{\mathrm{m}}} \frac{\partial\left(\Delta \theta_{\mathrm{m}}\right)}{\partial x}=\boldsymbol{F}_{\mathbf{S}, \mathrm{x}}+F_{\alpha}+\boldsymbol{F}_{\mathbf{I}, \mathbf{x}}+\boldsymbol{F}_{\mathbf{D I}, \mathrm{x}}
\end{aligned}
$$

with $\alpha=-\partial z_{\mathrm{s}} / \partial x$.

One important parameter for the evaluation of these equations is the height of the katabatic wind layer. The approaches to determine $h$ are similar for numerical model data and aircraft measurements. While the aircraft vertical profiles flown between $\mathrm{Pa}$ and $\mathrm{Pb}$ (Fig. 2) have a much higher vertical resolution than the model data, their vertical extent is limited to about $400 \mathrm{~m}$ above the surface. As in Heinemann (1999), the SBL height is derived taking the vertical gradient of the potential temperature as the main criterion. In other words, $h$ is taken as the height of the surface inversion $h_{\mathrm{T}}$, using limits of $\partial \theta / \partial z=2 \mathrm{~K} / 100 \mathrm{~m}$ and $\partial \theta / \partial z=$ $1.5 \mathrm{~K} / 100 \mathrm{~m}$ for NORLAM and aircraft profiles, respectively. Since the lowest few decametres can be almost neutrally stratified during strong katabatic wind conditions, the minimum value for $h$ was set to 120 and $100 \mathrm{~m}$ for model and aircraft data, respectively (the main reason for these differences is the different vertical resolution of both types of data). Typical values for $h_{\mathrm{T}}$ are between 100 and $200 \mathrm{~m}$.
The superimposed synoptic (free atmosphere) pressure gradient was also evaluated from both data sets. NORLAM has the advantage that pressure data are available on terrain following coordinates between $10 \mathrm{~m}$ agl and $100 \mathrm{hPa}$. The synoptic pressure gradient was derived at $1000 \mathrm{~m}$ agl, which is well above the SBL. The variation of the synoptic pressure gradient between the top of the boundary layer over the ice sheet (about $200 \mathrm{~m}$ ) and the chosen level of $1 \mathrm{~km}$ was found to be relatively small. Since the aircraft profiles did not reach this height, the wind measured above $h+50 \mathrm{~m}$ was assumed to represent free atmosphere flow, and averages of the potential temperature and the wind components $u_{\mathrm{g}}$ and $v_{\mathrm{g}}$ are obtained as means for heights above $h+50 \mathrm{~m}$. The temperature deficit is computed as the difference between mean the free atmosphere potential temperature above the katabatic wind layer (which is almost constant with height) and the mean potential temperature of the katabatic wind layer.

\section{Case study of katabatic wind dynamics during KABEG}

The katabatic wind case investigated by aircraft measurements on 22 April 1997 represents an example of the katabatic wind system under strong synoptic forcing, since relative high wind speeds are found for the free atmosphere (Heinemann, 1999; Klein et al., 2001). Figure 3 shows the NORLAM simulation of the katabatic wind regime for Greenland 0600 UTC 22 April 1997. The $30 \mathrm{~h}$ simulation of LAM25 for wind vector at the lowest sigma level $(10 \mathrm{~m}$ above the ground) shows the fully developed katabatic wind system. The dominant influence of the orography structure on the near-surface wind field is obvious. While a fairly homogeneous wind field with wind speeds around $15 \mathrm{~m} \mathrm{~s}^{-1}$ is found over West Greenland (and the KABEG area) over a scale of several hundred kilometres, channeling effects are present in areas of coastal valleys in East Greenland. Very pronounced channeling effects occur near Tasiilaq (Angmagssalik) at the coast of East Greenland, where the above-mentioned Piteraqs occur.

The topographic forcing term $\boldsymbol{F}_{\mathbf{T}}$ is displayed in Fig. 4a for 0600 UTC, 22 April 1997. $\boldsymbol{F}_{\mathbf{T}}$ is strong over the ice sheet slopes of South Greenland, but shows only small values over the central and northern parts of Greenland. Large values are present north of the Kangerlussuaq area, where a strong inversion with 


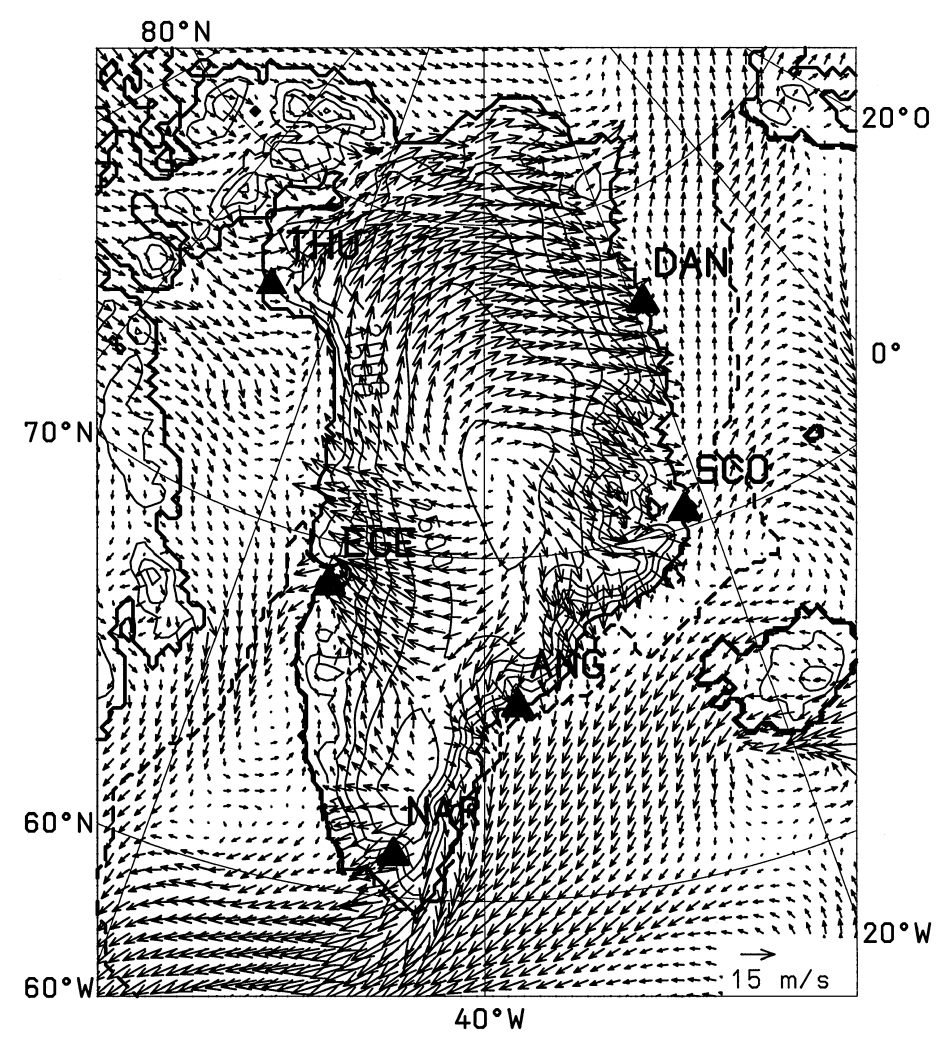

Fig. 3. Wind vectors at a height of $10 \mathrm{~m}$ (only every second vector plotted, reference vector in lower right corner) for a $30 \mathrm{~h}$ LAM25 forecast for 0600 UTC 22 April 1997 and orography (isolines every $500 \mathrm{~m}$ ). The thick line shows the coast line according to the model resolution, while the thick dashed line marks the ice edge. Greenland radiosonde stations are marked by triangles.

values of $\Delta \theta_{\mathrm{m}}$ up to $10 \mathrm{~K}$ is simulated (in the Kangerlussuaq area, the temperature deficit is about $6-8 \mathrm{~K}$, see below). Over the northern part of the ice sheet, the katabatic forcing is about zero as a result of clouds and a missing inversion.

The results for this realistic case can be compared with an idealized wintertime simulation without synoptic forcing and without clouds. In this model run, the atmosphere is initially at rest, and wintertime radiation conditions and sea ice coverage according to 1 January 1990 are assumed (details about this model run can be found in Klein and Heinemann, 2002). In this idealized simulation, katabatic winds with speeds of up to $16 \mathrm{~m} \mathrm{~s}^{-1}$ develop over all slopes of the ice sheet after $24 \mathrm{~h}$ of integration (see Fig. 4 in Klein and Heinemann, 2002). Figure $4 \mathrm{~b}$ shows the acceleration of the katabatic wind by the forcing term $\boldsymbol{F}_{\mathbf{T}}$ after $24 \mathrm{~h}$ for this idealized simulation. While the acceleration is relatively weak on top of the ice sheet, the largest val- ues of up to $40 \times 10^{-4} \mathrm{~m} \mathrm{~s}^{-2}$ are found in the coastal areas, where the strongest orographical gradients are present. The computed boundary layer heights vary between 130 and $390 \mathrm{~m}$, while the computed inversion strength varies between 2 and $8 \mathrm{~K}$. The contributions of the accelerations $\boldsymbol{F}_{\mathbf{I}}, \boldsymbol{F}_{\mathrm{DI}}, \boldsymbol{F}_{\mathbf{S}}$, and the advection of momentum are small, while the Coriolis term $\boldsymbol{F}_{\mathbf{C}}$ and the friction term $\boldsymbol{F}_{\mathbf{R}}$ are important (not shown). In contrast to the realistic simulation (Fig. 4a), the katabatic forcing is also present over the northern part of the ice sheet, since no clouds develop in the idealized simulation.

A cross-section of the different contributions of the one-dimensional pressure gradient term [Eq. (3)] for the LAM25 simulation valid at 0600 UTC 22 April 1997 is shown in Fig. 5 (position marked in Fig. 4a). The cross-section is oriented in about a west-east direction and is almost parallel to the KABEG measurement line $\mathrm{Pa}-\mathrm{Pb}$ (Fig. 2). The orography gradient has 

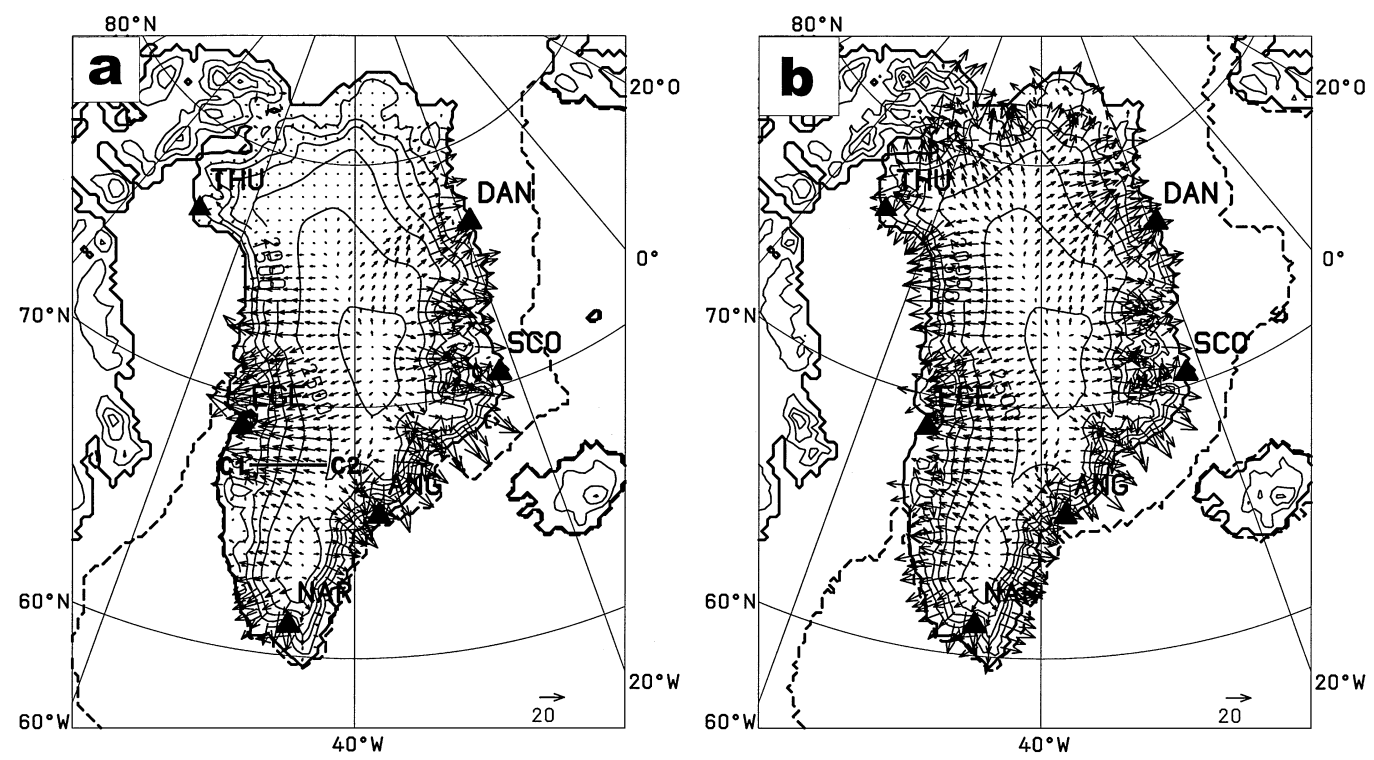

Fig. 4. Classical acceleration term of the katabatic wind $F_{\mathrm{T}}$ for the LAM 25 simulation after $30 \mathrm{~h}$ of integration valid at 0600 UTC 22 April 1997 (a) and for an idealized LAM25 simulation (atmosphere at rest) after $24 \mathrm{~h}$ of integration (b). Only every second vector is plotted, a reference vector of $20 \times 10^{-4} \mathrm{~m} \mathrm{~s}^{-2}$ is given in the lower right corner. The orography is plotted with full isolines (every $500 \mathrm{~m}$ ).

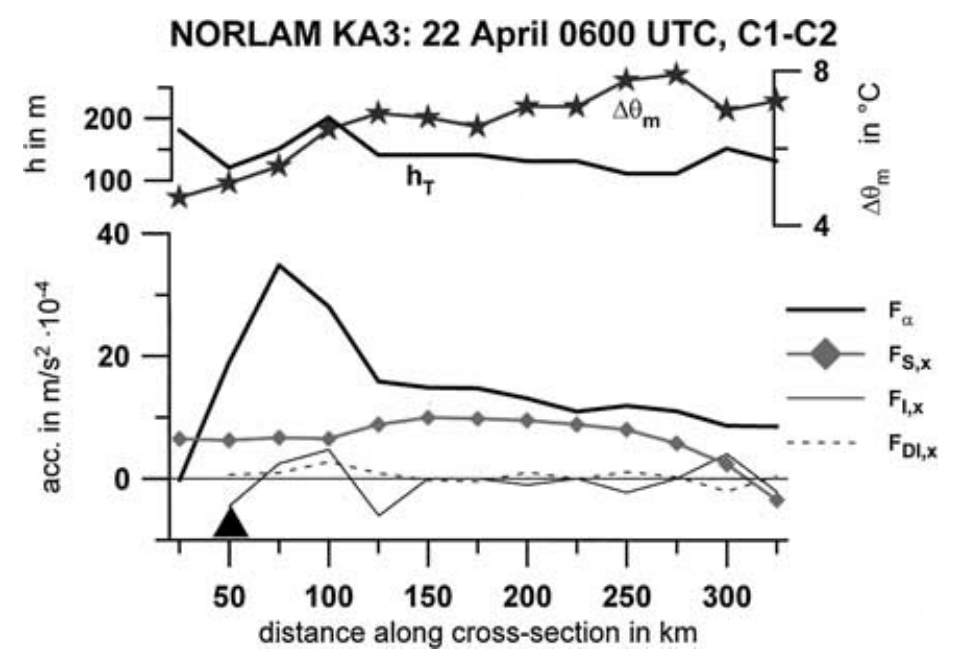

Fig. 5. Cross-section of model-derived quantities along the line C1-C2 marked in Fig. 4a at 0600 UTC 22 April 1997. Upper panel: height of the stable boundary layer $h_{\mathrm{T}}$ and temperature deficit $\Delta \theta_{\mathrm{m}}$. Lower panel: accelerations according to Eqs. (2) and (3). The position of the ice edge in the model is marked by a full triangle.

a maximum value of nearly $2 \%$ and decreases higher up over the ice sheet (not shown). The temperature deficit $\Delta \theta_{\mathrm{m}}$ varies only moderately between about 5 and $8 \mathrm{~K}$ and increases with higher orography. The SBL height varies between 110 and $200 \mathrm{~m}$, and is largest close to the ice edge. The katabatic acceleration term $F_{\alpha}$ along the cross-section is mainly determined by the slope variation, since the inversion strength varies over a much smaller range. The synoptic pressure gradient acceleration $F_{\mathrm{S}, \mathrm{x}}$ over the sloped ice sheet is in general 


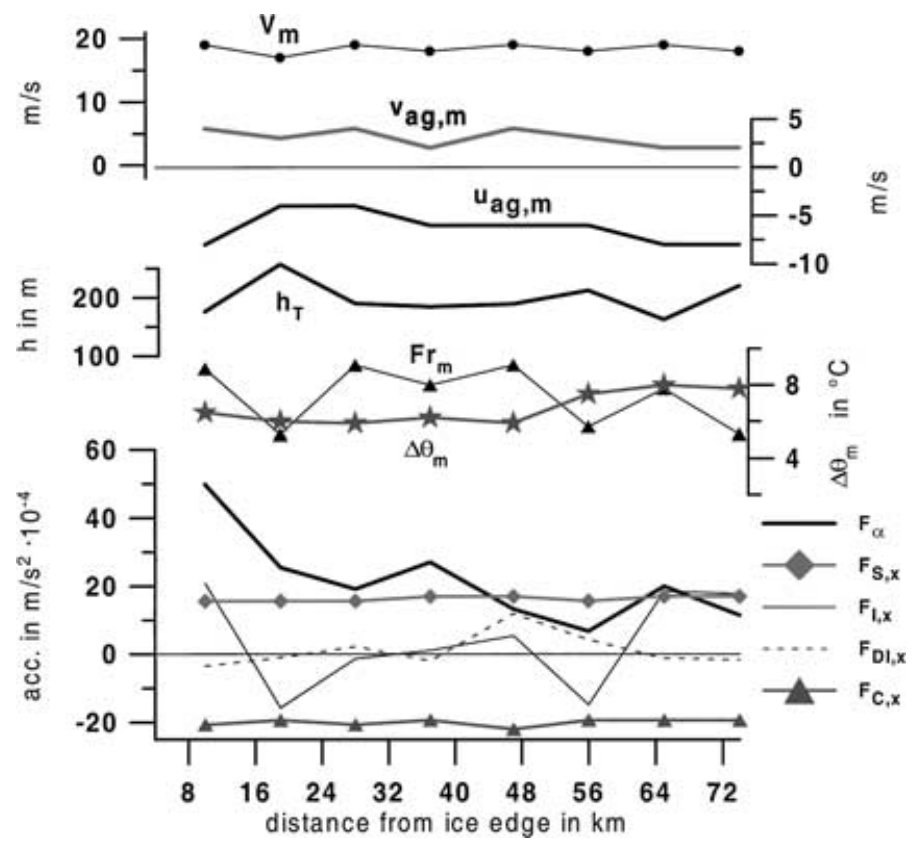

Fig. 6. Cross-section of aircraft-derived quantities between 0720-0740 UTC 22 April 1997 along line $\mathrm{Pa}-\mathrm{Pb}$ (Fig. 2) analyzed according to the integrated boundary layer model (only over the ice sheet, distance from the ice edge as horizontal coordinate). Upper panel: mean boundary layer wind speed $V_{\mathrm{m}}$, and the ageostrophic wind components $u_{\mathrm{ag}, \mathrm{m}}$ and $v_{\mathrm{ag}, \mathrm{m}}$. Middle panels: height of the stable boundary layer $h_{\mathrm{T}}$, temperature deficit $\Delta \theta_{\mathrm{m}}$ and the Froude number $\left(F r_{\mathrm{m}}\right.$, same scale as $\left.\Delta \theta_{\mathrm{m}}\right)$. Lower panel: accelerations according to Eqs. (2) and (3).

smaller than $F_{\alpha}$, with maximum absolute values of about $10 \times 10^{-4} \mathrm{~m} \mathrm{~s}^{-2}$. The term $F_{\mathrm{DI}, \mathrm{x}}$ is generally small, with a magnitude of less than $5 \times 10^{-4} \mathrm{~m} \mathrm{~s}^{-2}$, while $F_{\mathrm{I}, \mathrm{x}}$ is only important in regions with a strong variation of the boundary layer height.

Vertical profiles of the boundary layer were flown by the KABEG aircraft between 0720-0740 UTC 22 April 1997 along line $\mathrm{Pa}-\mathrm{Pb}$ (Fig. 2). Figure 6 shows a cross-section of aircraft-derived quantities analyzed according to the integrated boundary layer model. The mean wind speed $V_{\mathrm{m}}$ in the katabatic wind layer is about $20 \mathrm{~m} \mathrm{~s}^{-1}$ and is almost constant over the slope. Since a significant acceleration by the synoptic pressure gradient was present for this case, it is interesting to separate the influence of the synoptic pressure gradient on the wind vector in the SBL. This is achieved by computing the mean ageostrophic wind in the SBL as the difference between mean wind vector $\boldsymbol{V}_{\mathbf{m}}$ and the mean geostrophic wind above the SBL. As in Heinemann (1999), this was done in the conventional meteorological system ( $x$-axis pointing to the east), i.e. a negative $u_{\mathrm{ag}, \mathrm{m}}$ represents an excess in downslope wind. While the ageostrophic anomaly of the north- ward wind component is positive and relatively small (2-3 $\left.\mathrm{m} \mathrm{s}^{-1}\right)$, the main contribution of the boundary layer to the wind speed can be seen in the ageostrophic component of the eastward component, with absolute values of up to $8 \mathrm{~m} \mathrm{~s}^{-1}$. The SBL height $h_{\mathrm{T}}$ is around $200 \mathrm{~m}$, and the temperature deficit $\Delta \theta_{\mathrm{m}}$ shows a slight increase from $6 \mathrm{~K}$ near the ice edge to $8 \mathrm{~K}$ higher up the slope. The mean Froude number $F r_{\mathrm{m}}$ of the SBL was computed from the integrated quantities. In accordance with the results shown in Heinemann (1999), $F r_{\text {m }}$ values are well above 1.0, reflecting that the flow is shooting (Ball, 1956).

The katabatic force $F_{\alpha}$ (values in $10^{-4} \mathrm{~m} \mathrm{~s}^{-2}$ ) shows a strong decrease between the ice edge and the higher part of the slope. $F_{\alpha}$ exceeds the contribution of the synoptic pressure gradient $F_{\mathrm{S}, \mathrm{x}}$ for the lowest $40 \mathrm{~km}$ of the slope. $F_{\mathrm{S}, \mathrm{x}}$ is almost constant and acts as intensifying the downslope flow, but is overcompensated by the Coriolis force $F_{\mathrm{C}, \mathrm{x}}$. The acceleration due to the variation of the inversion strength $F_{\mathrm{DI}, \mathrm{x}}$ is of minor importance in general, while the variation of the inversion height $F_{\mathrm{I}, \mathrm{x}}$ becomes relatively more important over the upper part of the slope. 


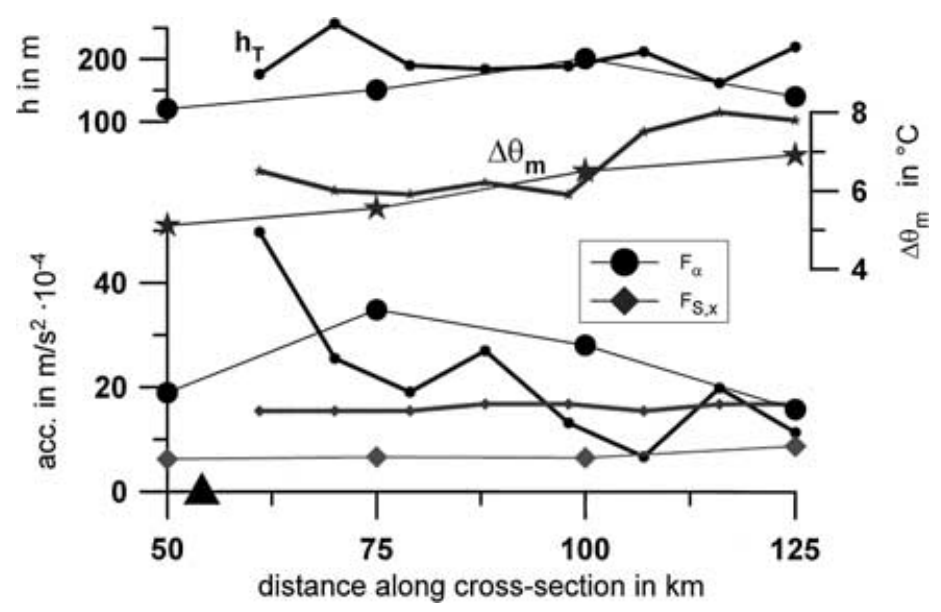

Fig. 7. Co-located cross-sections of model-derived (large symbols, thin lines) and aircraft-derived (small symbols, thick lines) quantities along the line C1-C2 marked in Fig. 5 at 0600 UTC 22 April 1997 (LAM25) and 0720-0740 UTC 22 April 1997 (aircraft). Upper panels: height of the stable boundary layer $h_{\mathrm{T}}$ and temperature deficit $\Delta \theta_{\mathrm{m}}$. Lower panel: accelerations according to Eqs. (2) and (3). The position of the ice edge in the observations is marked by a full triangle.

A comparison of Figs. 5 and 6 yields good qualitative agreement with respect to the variation of most quantities along the slope. A direct comparison of colocated aircraft and LAM25 data is shown in Fig. 7. Since the ice edge is different in the model and in the aircraft observations, the co-location was achieved by a projection of the model grid points to the aircraft leg. The quantitative comparison of $h_{\mathrm{T}}$ and $\Delta \theta_{\mathrm{m}}$ shows very good agreement. The contribution of the synoptic pressure gradient $F_{\mathrm{S}, \mathrm{x}}$ is systematically underestimated by the model. The decrease of $F_{\alpha}$ with height (increasing distance to the ice edge) over the upper part of the slope is well simulated, but $F_{\alpha}$ is too large. In contrast, the high values of $F_{\alpha}$ close to the (real) ice edge are not captured by the LAM 25 data. This latter result can be explained by the fact that the orography gradient is smoothed out in the model because of the (in this particular area) too low/coarse horizontal resolution. Considering that the horizontal resolution of the model is about five times coarser than the distance between two consecutive aircraft profiles, it can be concluded that the model has the ability to simulate the katabatic wind dynamics of this case realistically.

\section{Katabatic wind dynamics for a complete winter month}

NORLAM simulations in a forecast mode were performed for the winter month January 1990 (snow- covered tundra). January 1990 is a month with a relatively high value of the NAO (North Atlantic Oscillation) index, i.e. an unusually large monthly mean pressure gradient between Iceland and the Azores. In order to allow for a sufficient spinup time of the mesoscale model nested in the ECMWF analyses, only the second day of the NORLAM forecasts is used. The monthly mean sea level pressure (MSLP) field computed from NORLAM LAM50 output after 30, 36, 42 and $48 \mathrm{~h}$ for each day is displayed in Fig. 8. The synoptic conditions of this month were characterized by several intense cyclones near Iceland, which led to a pronounced low in the mean field with its center located southwest of Iceland (indicated by 'L' in Fig. 8). This monthly mean synoptic-scale low with a minimum pressure of $981 \mathrm{hPa}$ is in agreement with the ECMWF analyses and is also captured well in the LAM25 simulations (not shown).

The mean $10 \mathrm{~m}$ winds simulated by LAM 25 for January 1990 are shown in Fig. 9. Apart from the southeastern part of Greenland between Narssassuaq (NAR) and Angmagssalik (ANG), where the impact of the mean low is largest, there is a clear signal of the katabatic wind system in the mean wind fields. Mean wind speeds over the ice reach maximum values of up to $14 \mathrm{~m} \mathrm{~s}^{-1}$. The strongest katabatic winds occur north of about $70^{\circ} \mathrm{N}$ on the western side of Greenland and north of about $75^{\circ} \mathrm{N}$ along the eastern part of Greenland, where the influence of the synoptic low is less strong. While in the idealized simulation for 


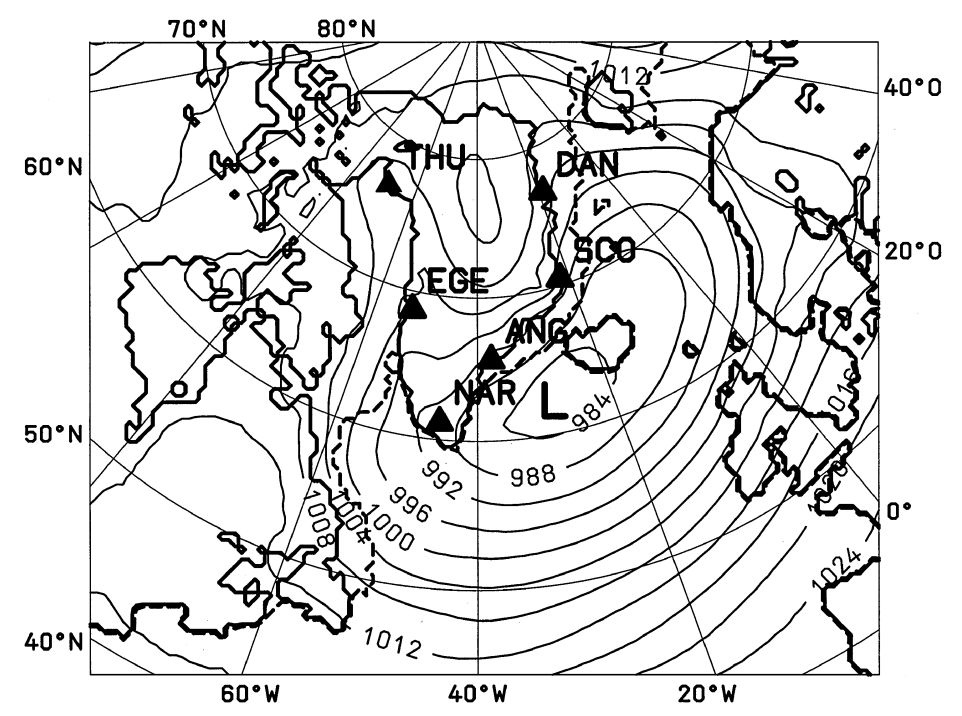

Fig. 8. Monthly mean of MSLP for the LAM50 simulation of January 1990 (isolines every $4 \mathrm{hPa}$ ). The thick line shows the coast line according to the model resolution of the LAM50, while the thick dashed line indicates the sea ice front. The center of the mean low pressure system southwest of Iceland is marked by 'L'. Greenland radiosonde stations are indicated by triangles.

January 1990 presented by Klein and Heinemann (2002) a pronounced channeling of the flow occurs in areas with significant valley structures along the eastern coast of Greenland, this channeling is only weakly developed in the monthly simulation of January 1990 due to the mean synoptic low near Iceland. Another result of the positive NAO situation of January 1990 is the absence of a signal of the katabatic wind in the monthly mean fields along the southeastern coast. Though this area is well known for intense katabatic winds (especially in the valley region near Angmagssalik/Tassiilaq, see Introduction), the katabatic winds do not seem to be persistent in terms of longer periods, i.e. more than one or two days, due to the frequency of synoptic-scale disturbances near Iceland. Since the katabatic winds in the southeastern part of Greenland are well developed in idealized simulations without synoptic forcing, and since they can be very intense in individual cases, the simulation for January 1990 indicates the great importance of the synoptic conditions for the development of the katabatic winds. This is confirmed by an investigation of the individual model forecasts of January 1990, which shows that there were only few and relatively short katabatic wind episodes along the southeastern part of Greenland during this month. This can also be seen from an analysis of the directional constancy of the winds in January 1990. The directional constancy is computed as the ratio of the absolute value of the vector mean of the model winds (output every $6 \mathrm{~h}$ ) to the scalar mean of wind speed. In Fig. 9 the directional constancy for January 1990 is also shown. Values below 0.8 are present around Greenland (with the exception of Davis Strait west of Greenland), where the winds are mainly of synoptic nature, and on top of Greenland, where the slope is negligible. Over the Davis Strait surprisingly persistent northerly winds were simulated, indicating that the Davis Strait region is favourable for Arctic cold air outbreaks. Over the steeper slopes the directional constancy is larger than 0.8 and over most parts of the ice sheet even larger than 0.9. An exception is South Greenland, where the impact of transient synoptic cyclones leads to a larger variability of the wind direction during that month.

The Ball model was also used to derive acceleration components from the monthly mean data obtained from the NORLAM forecasts covering January 1990. The katabatic contribution $\boldsymbol{F}_{\mathbf{T}}$ is displayed in Fig. 10a. The monthly mean katabatic acceleration in North Greenland resembles very much the idealized case (Fig. 4b). In South Greenland, however, the force $\boldsymbol{F}_{\mathbf{T}}$ is significantly smaller than in the case without synoptic forcing. This result consequently explains the structure of the mean wind field in January 1990 


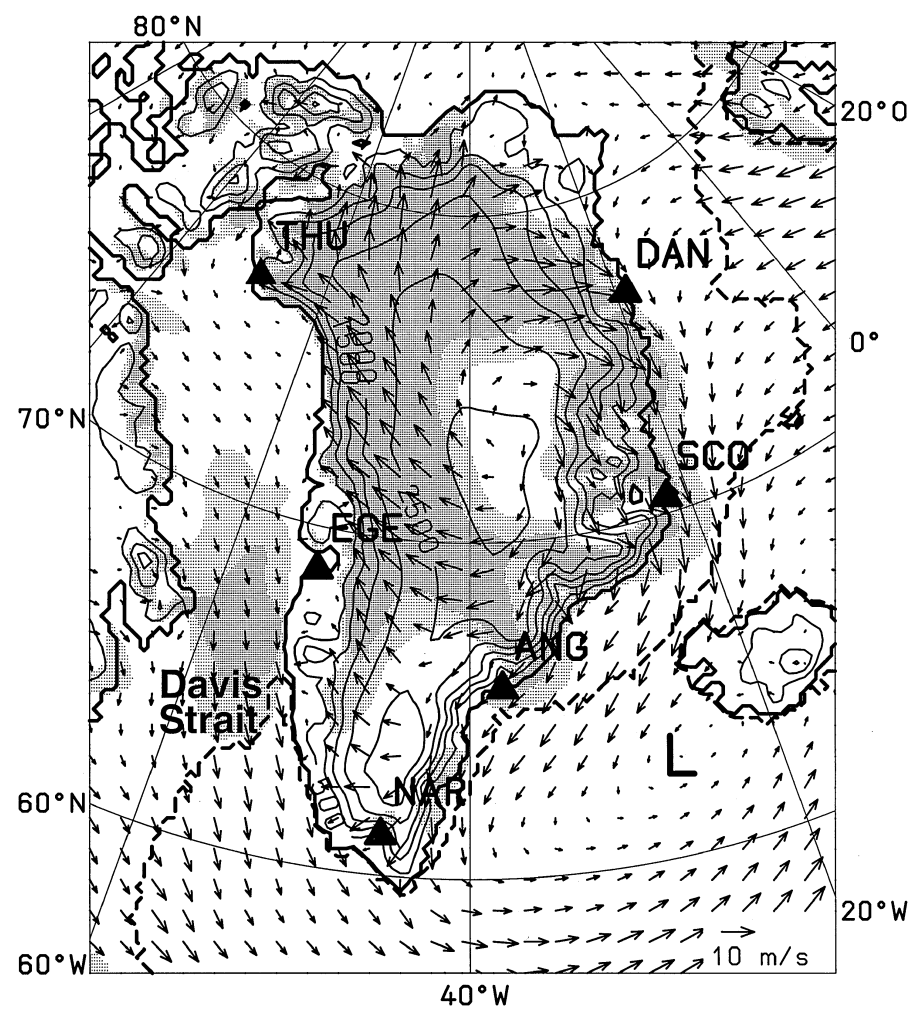

Fig. 9. As Fig. 3, but for the monthly mean of January 1990 and with only every fourth wind vector plotted. In addition, the directional constancy on a timescale of $6 \mathrm{~h}$ (related to the monthly mean) is represented by shading: light shading corresponds to values between 0.8 and 0.9 , while dark shading indicates values larger than 0.9. Davis Strait is indicated. The center of the mean low pressure system southwest of Iceland is marked by ' $\mathrm{L}$ '.

(Fig. 9). The reason for the weak katabatic acceleration in South Greenland is the weakly pronounced inversion in that area. In Fig. 10b the monthly mean inversion strength is shown, explaining the horizontal distribution of the acceleration $\boldsymbol{F}_{\mathbf{T}}$ and the nearsurface wind field. This weaker inversion strength in South Greenland has to be attributed to the impact of transient synoptic cyclones and the associated cloud patterns. An analysis of the mean total cloud coverage (not displayed) shows values of more than $70 \%$ over Southeast Greenland, while the other areas over the ice sheet apart from the region near Summit are less clouded. Strong synoptic pressure gradients $F_{\mathrm{S}}$ are present during January 1990 (Fig. 10c). The pressure gradient associated with the mean low-pressure system near Iceland is clearly visible. The ice slopes along the southeastern coast (south of Angmagssalik, Fig. 1) can be seen as areas with small katabatic as well as small synoptic pressure gradients. Over the adjacent ocean, the frictional force is much weaker compared to the SBL over the ice sheet, and consequently, the nearsurface flow is oriented almost parallel to the coast. The pressure gradient force over the northwestern part of the Greenland (between the Kangerlussuaq area and Thule, Fig. 1) ice sheet points in the direction of the local katabatic force $\boldsymbol{F}_{\mathbf{T}}$, which explains the relatively strong monthly mean near-surface winds over the ice (Fig. 9). Over the southwestern and northeastern (north of Danmarkshavn, Fig. 1) parts of Greenland, however, no significant synoptic support of the katabatic winds can be seen, and $\boldsymbol{F}_{\mathbf{S}}$ is even opposed to $\boldsymbol{F}_{\mathbf{T}}$ in some regions.

\section{Summary and conclusions}

The structure and dynamics of the Greenland katabatic wind system are investigated by means of 

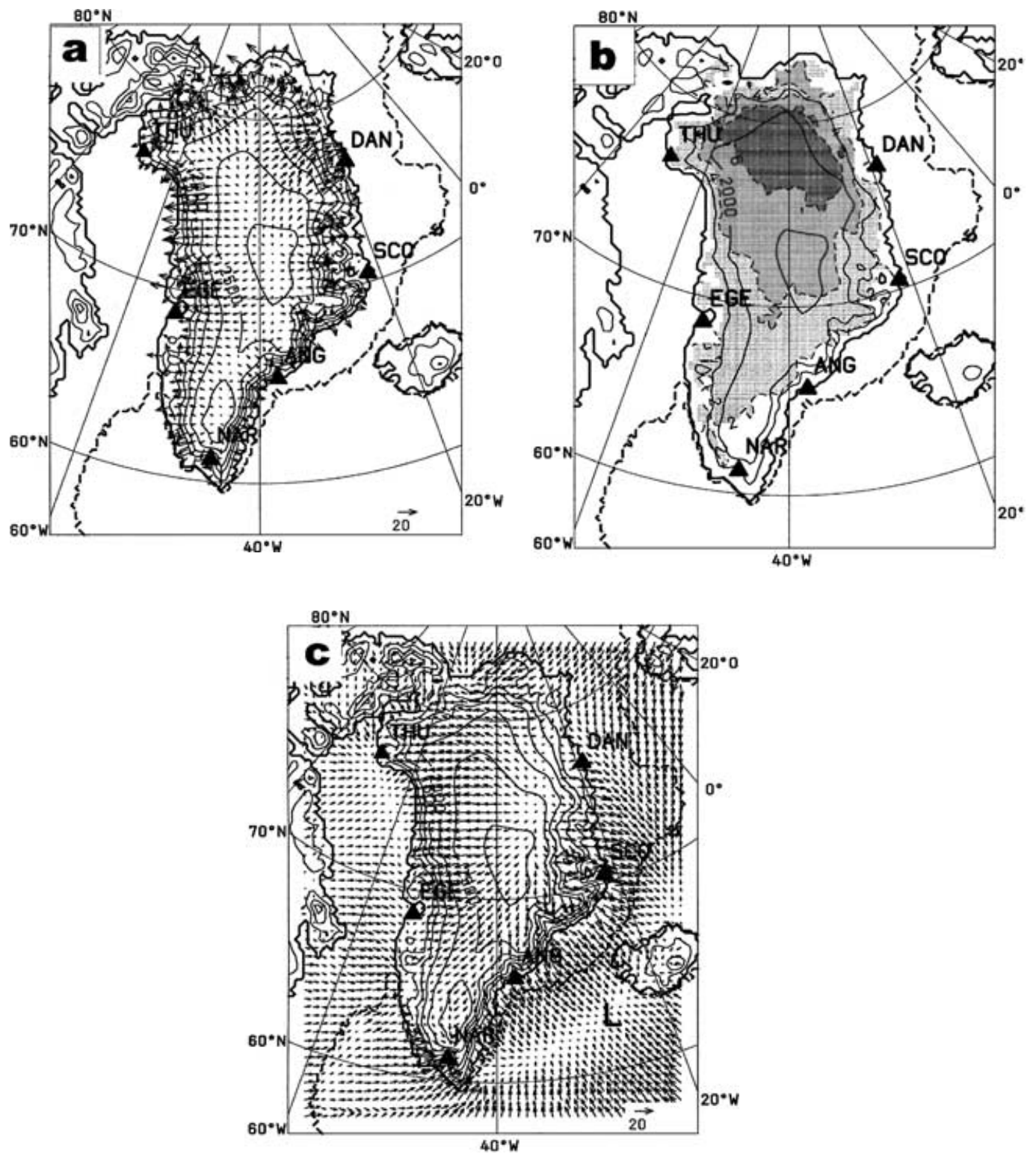

Fig. 10. (a) As Fig. 4, but for the monthly mean of January 1990. (b) Monthly mean temperature deficit $\Delta \theta_{\mathrm{m}}$ (isolines every $2 \mathrm{~K}$, values larger than $2 \mathrm{~K}$ are shaded in $2 \mathrm{~K}$ intervals) and orography (full isolines every $1000 \mathrm{~m}$ ). (c) As (a), but for the January 1990 monthly mean of the synoptic acceleration $F_{\mathrm{S}}$. The center of the mean low pressure system southwest of Iceland is marked by ' $\mathrm{L}$ '.

NORLAM simulations and aircraft data of the KABEG experiment. The KABEG case of a strong katabatic wind system on 22 April 1997 is examined in detail, and a complete winter month (January 1990) is simulated. The Ball (1956) model was used to gain insight into the horizontal distribution of the main acceleration components governing katabatic flow over the Greenland ice sheet.

The NORLAM is able to simulate the structures of the katabatic wind system in the lowest $400 \mathrm{~m}$ 
realistically. Terms of the momentum budget integrated over the boundary layer agree well with aircraft measurements for the KABEG case. The pure katabatic force resulting from the gradient of orography and the inversion strength represents one of the most important forcing terms in the momentum budget. Consequently, the steeper coastal margins of Greenland can be identified as areas with the largest katabatic potential. However, a considerable influence of the large-scale synoptic forcing is found as well, which has the same importance as the pure katabatic force for the upper parts of the ice slope.

The monthly averaged simulation results for January 1990 show a clear signal of the katabatic wind system for large parts of the ice sheet area. Comparisons of the January 1990 mean to an idealized simulation without synoptic forcing confirm that the poor development of the katabatic wind in Southeast Greenland is a result of the specific synoptic conditions during that month. In the case of January 1990 (high NAO), a strong mean low pressure system southwest of Iceland prevented a significant katabatic wind development in the southeast of Greenland (considering the monthly mean). This result is very interesting, since it suggests that the katabatic wind system in that area of Greenland might generally not be as persistent as in other parts of Greenland. This seems to be due to the frequency of synoptic disturbances near Southern Iceland which can oppose the katabatic development by a 'counter-katabatic' synoptic flow or by synoptic-scale cloudiness preventing a cooling of the near surface air. This result is no contradiction to the accepted fact that the katabatic winds in Southeast Greenland can become very intense in individual cases under specific synoptic conditions, which is also demonstrated by the case studies of Klein and Heinemann (2002). In the monthly mean of January 1990, the boundary layer temperature deficit is only weakly pronounced with values of about $2 \mathrm{~K}$ or less in South/Southeast Greenland (compared to $6 \mathrm{~K}$ in North Greenland), which consequently leads to weaker katabatic acceleration and weaker katabatic winds in that area. In contrast, katabatic and synoptic forcing act in the same way over the ice sheet of West and Northwest Greenland, leading to a strong and persistent nearsurface flow in these areas.

\section{Acknowledgements}

KABEG was supported by the German Federal Ministery of Education, Science, Research and Technology under grant BMBF-03PL020F, the aircraft program was funded by the Alfred-Wegener-Institut (AWI). The numerical simulations were supported by the Deutsche Forschungsgemeinschaft under grant He 2740/1. The ECMWF provided the analyses taken as initial and boundary conditions for the simulations. The Norwegian Meteorological Institute (DNMI) at Oslo made the NORLAM model available. SSM/I data used for the derivation of the sea ice coverage for April 1997 were provided by the Global Hydrology Resource Center (GHRC) at the Global Hydrology and Climate Center (Huntsville, Alabama, USA). SSM/I-derived sea ice coverage for January 1990 was provided by the National Snow and Ice Data Center (NSIDC) at Boulder, Colorado.

\section{REFERENCES}

Ball, F. K. 1956. The theory of strong katabatic winds. Aust. J. Phys. 9, 373-386.

Bromwich, D. H., Du, Y. and Parish, T. R. 1994. Numerical simulation of winter katabatic winds from West Antarctica crossing Siple Coast and the Ross Ice Shelf. Mon. Wea. Rev. 122, 1417-1435.

Bromwich, D. H., Du, Y. and Hines, K. M. 1996. Wintertime surface winds over the Greenland ice sheet. Mon. Wea. Rev. 124, 1941-1947.

Bromwich, D. H., Cassano, J. J., Klein, T., Heinemann, G., Hines, K. M., Steffen, K. and Box, J. E. 2001. Mesoscale modeling of katabatic winds over Greenland with polar MM5. Mon. Wea. Rev. 129, 2290-2309.

Ekholm, S. 1996. A full coverage, high-resolution, topographic model of Greenland computed from a variety of digital elevation data. J. Geophys. Res. 101, 21961-21972.
Grønås, S. and Hellevik, O. E. 1982. A limited area prediction model at the Norwegian Meteorological Institute. Technical Report No. 61, ISSN 0332-9879, The Norwegian Meteorological Institute, Oslo, Norway, $75 \mathrm{pp}$.

Grønås, S. and Skeie, P. 1999. A case study of strong winds at an arctic front. Tellus $\mathbf{5 1 A}, 865-879$.

Grønås, S., Foss, A. and Lystad, M. 1987. Numerical simulations of polar lows in the Norwegian Sea. Tellus 39A, 334-353.

Heinemann, G. 1998. Katabatic wind and boundary layer front experiment around Greenland (KABEG) field phase report. Reports on Polar Research 269, Alfred-WegenerInstitute for Polar Research, Bremerhaven, Germany, $93 \mathrm{pp}$.

Heinemann, G. 1999. The KABEG'97 field experiment: an aircraft-based study of the katabatic wind dynamics over 
the Greenlandic ice sheet. Boundary Layer Meteorol. 93, 75-116.

Heinemann, G. 2002. Aircraft-based measurements of turbulence structures in the katabatic flow over Greenland. Boundary Layer Meteorol. 103, 83-116.

Klein, T. and Heinemann, G. 2002. Interaction of katabatic winds and mesocyclones at the eastern coast of Greenland. Meteorol. Appl., in press.

Klein, T., Heinemann, G., Bromwich, D. H., Cassano, J. J. and Hines, K. M. 2001. Mesoscale modeling of katabatic winds over Greenland and comparisons with AWS and aircraft data. Meteorol. Atmosph. Phys. 78, 115-132.

Mahrt, L. 1982. Momentum balance of gravity flows. $J$. Atmos. Sci. 39, 2701-2711.

Nordeng, T. E. 1986. Parameterization of physical processes in a three-dimensional numerical weather prediction model. Technical Report No. 65, ISSN 0332-9879, The Norwegian Meteorological Institute, Oslo, Norway, $48 \mathrm{pp}$.

Oerlemans, J. and Vugts, H. 1993. A meteorological experi- ment in the ablation zone of the Greenland ice sheet. Bull. Am. Meteorol. Soc. 74, 355-365.

Parish, T. R. and Bromwich, D. H. 1987. The surface wind field over the Antarctic ice sheets. Nature 328, 5154.

Rasmussen, L. 1989. Greenland winds and satellite imagery. Vejret, Danish Meteorological Society, 32-37.

Van den Broeke, M. R., Duynkerke, P. G. and Henneken, E. A. C. 1994. Heat, momentum and moisture budgets of the katabatic layer over the melting zone of the west Greenland ice sheet in summer. Boundary-Layer Meteorol. 71, 393-413.

Van den Broeke, M. R. and Gallée, H. 1996. Observation and simulation of barrier winds at the western margin of the Greenland ice sheet. Quart. J. R. Meteorol. Soc. 122, 1365-1383.

Van den Broeke, M. R., van Lipzig, N. P. M. and van Meijgaard, E. 2002. Momentum budget of the East-Antarctic atmospheric boundary layer: results of a regional climate model. J. Atmos. Sci., in press. 